\title{
Mitral and Tricuspid Transcatheter Interventions Current Indications and Future Directions
}

\author{
Mirjam Gauri Winkel ${ }^{1}$, Fabien Praz ${ }^{1}$ and Peter Wenaweser ${ }^{1,2 *}$ \\ ${ }^{1}$ Department of Cardiology, Inselspital, Bern University Hospital, University of Bern, Bern, Switzerland, ${ }^{2}$ Heart Clinic \\ Hirslanden Zurich, Zurich, Switzerland
}

Valvular heart disease is responsible for a high rate of morbidity and mortality, especially in the elderly population. With the emergence of new transcatheter treatment options, the therapeutic spectrum for patients with valvular heart disease has considerably expanded during the past years. Interventional treatment of the mitral and tricuspid valve requires an individualized and versatile approach owing to the different etiologies of valvular dysfunction and the complex anatomy of the atrioventricular valves. This article aims to review recent developments, summarize the evidence, indications and limitations of the available systems, and provide a glimpse into the future of transcatheter interventions for the treatment of mitral and tricuspid valve disease.

Keywords: valvular heart disease, mitral interventions, tricuspid interventions, cardioband, mitraclip, pascal, annuloplasty, edge-to-edge repair

OPEN ACCESS

Edited by: Crochan John O'Sullivan,

Triemli Hospital, Switzerland

Reviewed by:

Paolo Denti,

San Raffaele Hospital (IRCCS), Italy

Marco Barbanti,

University of Catania, Italy

*Correspondence:

Peter Wenaweser

peter.wenaweser@hirslanden.ch

Specialty section:

This article was submitted to Structural Interventional Cardiology,

a section of the journal

Frontiers in Cardiovascular Medicine

Received: 03 November 2019

Accepted: 25 March 2020

Published: 15 May 2020

Citation:

Winkel MG, Praz F and Wenaweser $P$ (2020) Mitral and Tricuspid Transcatheter Interventions Current Indications and Future Directions.

Front. Cardiovasc. Med. 7:61.

doi: 10.3389/fCvm.2020.00061

\section{INTRODUCTION}

Valvular heart disease is a common condition that has long been underappreciated although it has tremendous impact on mortality and morbidity. Population-based analyses have shown a prevalence of moderate to severe mitral and tricuspid valve disease of 9.3 and $4.0 \%$ in the elderly population, respectively $(1,2)$. The incremental annual costs for valvular heart disease in the US are substantial [estimated at $\$ 23.4$ billion (3)] and expected to further increase given population growing and aging.

In the past, a high proportion of patients with severe mitral or tricuspid valve disease has been denied treatment beyond medical therapy, mainly because of age and decreased left ventricular function, both associated with high surgical risk (4). Over the last years, the interventional landscape has widely expanded with new transcatheter methods emerging for both mitral and tricuspid valve treatment. In contrast to transcatheter aortic valve implantation, the interventional treatment of mitral and tricuspid valve disease requires a more versatile approach due to the different etiologies of valvular dysfunction. This article aims to review the evolution of the field, to discuss current indications and limitations and attempts to provide a glimpse to the future of transcatheter interventions for mitral and tricuspid valve disease.

\section{TRANSCATHETER MITRAL VALVE INTERVENTIONS}

\section{State of the Art}

The treatment of the mitral valve has long been exclusively based on surgical mitral valve repair or replacement. However, open-heart surgery has several limitations including low penetrance and increased mortality in elderly patients and those with diminished left ventricular function (5). To further improve patient care and expand the therapeutic options of severe mitral valve disease, minimal-invasive percutaneous solutions have been introduced into clinical practice. 
Current transcatheter interventions are mostly derived from surgical procedures. Based on their mode of action, they can be classified into four groups: leaflet approximation, direct and indirect annuloplasty, chordal, and valve replacement.

The MitraClip ${ }^{\circledR}$ (Abbott Vascular, Chicago, US) device is the first transcatheter technology with CE mark and FDA approval for the treatment of both primary and secondary MR (6). Since its first implantation in 2003, over 100,000 procedures have been performed worldwide. Owing to its minimal-invasive approach and limited interaction with the native anatomy, it carries a high safety profile and enables fast patient's recovery $(7,8)$.

The first randomized trial to assess the efficacy of the MitraClip system was the EVEREST II trial. Two hundred and seventy nine patients ( $27 \%$ with secondary MR) were assigned to either transcatheter or surgical treatment. At 5 years, there was no difference in terms of mortality between groups (20.8 vs. $26.8 \%$; $p=0.4$ ). In primary MR, the primary endpoint (freedom from death, MV surgery or reoperation, and $3+$ or $4+\mathrm{MR}$ ) occured more frequently in the transcatheter group (54.5 vs. $23.8 \%$; $p<$ 0.001 ), mainly driven by a higher rate of surgery for recurrent $\mathrm{MR}$, whereas there was no significant difference in patients with secondary MR (59.5 vs. $71.4 \%$; $p=0.43$ ). A landmark analysis beyond 6 months through 5 years showed comparable long-term durability with a rate of freedom from surgery for mitral valve dysfunction of $77.7 \%$ with MitraClip vs. $76.2 \%$ with surgery $(P=$ 0.77) (9).

In 2018, two randomized prospective trials comparing optimal medical treatment (OMT) alone to MitraClip in addition to OMT for patients with severe MR and heart failure have been presented. Despite high procedural success in the MitraClip group ( $92 \%$ with $\mathrm{MR} \leq 2+$ ), the French MITRA-FR study failed to show any difference for the primary composite endpoint of allcause mortality and hospitalization for heart failure throughout 2 years $(67.1 \%$ for OMT vs. $63.8 \%$ for MitraClip, HR 1.01) (10). In contrast, the US-American COAPT study showed a relative risk reduction of $47 \%$ (number needed to treat of 3.1) of the primary endpoint of rehospitalization for heart failure, as well as $37 \%$ of the secondary composite endpoint of rehospitalization or all-cause mortality after 2 years of followup. Procedural success was high (98\%), durable throughout 2 years (95\%), and the procedure was safe (no peri-procedural complications in $97 \%$ of patients) (11). Recently, the 3-year follow up data have been presented, reinforcing the previous results with an even larger symptomatic and survival benefit in the interventional group as compared to the OMT arm (12). Table 1 highlights the most important differences between the two studies.

The reasons for the different outcomes of these at first sight similar studies are the topic of an ongoing debate between experts coming from the interventional and heart failure community. When interpreting the above-mentioned results, the following factors need to be considered:

(1) Discrepancies in the definition of MR severity according to the European or American guidelines $(14,15)$,

(2) Exclusion of patients with severe left ventricular dilation as well as end stage heart failure in COAPT,
TABLE 1 | Key differences between the MITRA-FR and COAPT study [adapted from Praz et al. (13)].

\begin{tabular}{|c|c|c|}
\hline & MITRA-FR & COAPT \\
\hline $\begin{array}{l}\text { Patients } \\
\text { (screened) }\end{array}$ & $304(452)$ & $614(1,576)$ \\
\hline Age (years) & $70 \pm 10$ & $72 \pm 12$ \\
\hline \multirow[t]{6}{*}{$\begin{array}{l}\text { Key exclusion } \\
\text { criteria }\end{array}$} & $\begin{array}{l}\text { NYHA class } \\
<\|\end{array}$ & $\begin{array}{l}\text { NYHA class }<\| \text { Advanced heart } \\
\text { failure (ACC/AHA Stage D) }\end{array}$ \\
\hline & $\begin{array}{l}\text { CABG or PCl } \\
\text { within } 30 \\
\text { days }\end{array}$ & $\begin{array}{l}\text { Untreated CAD requiring } \\
\text { revascularization or } C A B G / P C l \\
\text { within } 30 \text { days }\end{array}$ \\
\hline & - & $\begin{array}{l}\text { Right-sided CHF with advanced } \\
\text { right ventricular dysfunction }\end{array}$ \\
\hline & - & $\begin{array}{l}\text { COPD with home oxygen } \\
\text { therapy or chronic oral steroid } \\
\text { use }\end{array}$ \\
\hline & - & Severe tricuspid regurgitation \\
\hline & - & $\begin{array}{l}\mathrm{sPAP}>70 \mathrm{mmHg} \text { unresponsive } \\
\text { to vasodilator therapy }\end{array}$ \\
\hline Mean LVEF (\%) & $33 \pm 7$ & $31 \pm 10$ \\
\hline MR EROA $\left(\mathrm{cm}^{2}\right)$ & $0.31 \pm 0.1$ & $0.41 \pm 0.15$ \\
\hline LVEDVi $\left(\mathrm{ml} / \mathrm{m}^{2}\right)$ & $135 \pm 35$ & $101 \pm 34$ \\
\hline Complications $(\%)^{*}$ & 14.6 & 8.5 \\
\hline $\begin{array}{l}\text { Death or } \\
\text { hospitalization for } \\
\text { HF at } 1 \text { year (\%) }\end{array}$ & 54.6 & 33.9 \\
\hline OMT & 51.3 & 46.5 \\
\hline $\begin{array}{l}\text { Death or } \\
\text { hospitalization for } \\
\text { HF at } 2 \text { years (\%) }\end{array}$ & 63.8 & 45.7 \\
\hline OMT & 67.1 & 67.9 \\
\hline
\end{tabular}

$C A D$, coronary artery disease; $P C l$, percutaneous coronary intervention; $C A B G$, coronary artery bypass grafting; CHF, congestive heart failure; COPD, chronic obstructive pulmonary disease; $L V E F$, left ventricular ejection fraction; $E R O A$, effective regurgitant orifice area; LVEDVi, indexed left ventricular end-diastolic volume; PHT, pulmonary hypertension; PAP, pulmonary artery pressure. ${ }^{\star}$ According to MITRA-FR definition.

(3) Supervision of OMT implementation by a central multidisciplinary committee in COAPT,

(4) Partly missing echocardiographic and clinical follow-up data in MITRA-FR.

Compared to COAPT, patients in MITRA-FR had a higher rate of peri-procedural complications (14.6 vs. $8.5 \%)$ as well as a lower rate of sustained MR reduction $(M R \leq 2+$ after 1 year in $83 \%$ of the patients vs. $95 \%$ in COAPT). This is noteworthy, since substudies of COAPT have shown residual MR (grade $3+/ 4+$ ) at 30-days to be a predictor of mortality at 2-years of follow-up.

While the state of knowledge from clinical trials and experience is constantly evolving, the MitraClip device itself has experienced only minor modifications, the most important being the introduction of the XTR system with extended clip arms in 2018 (16).

The PASCAL transcatheter mitral valve repair system (Edwards Lifesciences, Irvine, USA) has been developed to overcome some of the intrinsic technical limitations of the 

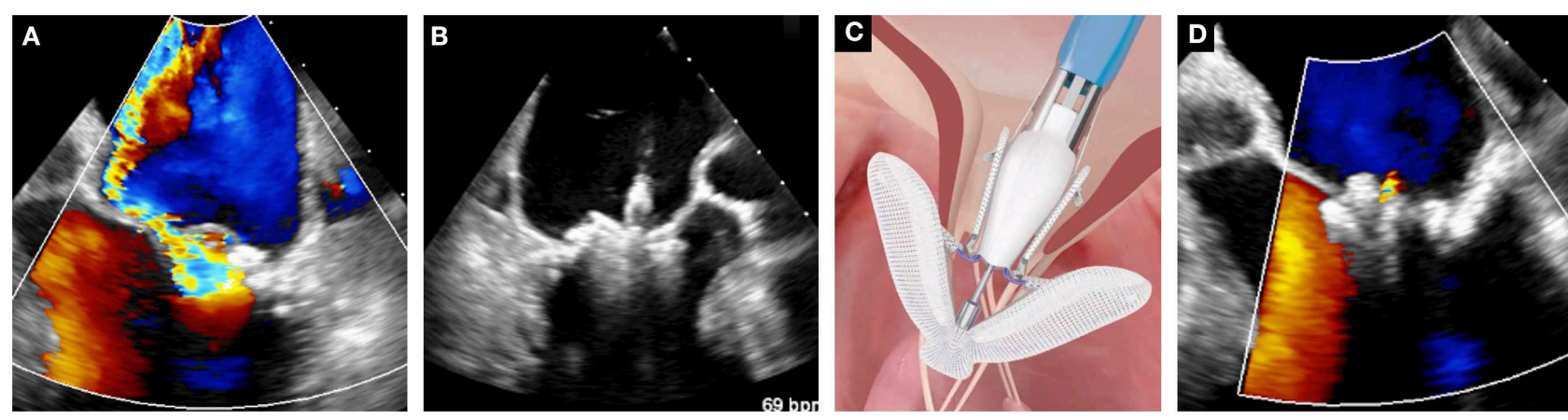

FIGURE 1 | Case of leaflet approximation with PASCAL device in secondary MR. (A) Baseline color-Doppler echocardiographic assessment of MR. (B) Leaflet clasping. (C) Schematic depiction of the PASCAL system (courtesy of Edwards Lifesciences). (D) Assessment of the final result with color Doppler echocardiography.

hitherto existing system. It has larger and longer arms, a central spacer designed to fill the coaptation defect and decrease the tension applied on the valve tissue, as well the capability to grasp each leaflet separately. After a preliminary encouraging compassionate experience in 23 patients (17), feasibility and efficacy in reducing MR have been recently confirmed in a multicenter prospective trial (18). Subsequently, the PASCAL system has gained CE mark in February 2019 for the treatment of both primary and secondary MR. Figure 1 shows an illustrative case of severe secondary MR successfully treated with implantation of one PASCAL implant.

Direct annuloplasty devices, anchored into the mitral valve annulus, and indirect annuloplasty devices aim to reduce annular dimensions and hence, increase leaflet coaptation in secondary MR. The Carillon Mitral Contour System ${ }^{\circledR}$ (Cardiac Dimensions, Kirkland US) was the first indirect annuloplasty device to receive CE mark (19). The recently published REDUCE FMR study was a randomized sham-controlled trial including 120 patients, which showed a statistically significant reduction in mitral regurgitant volume as well as left ventricular volumes in the interventional group compared to OMT alone (20). Over 800 procedures have been performed so far. Other indirect annuloplasty devices are under clinical evaluation, like the ARTO $^{\circledR}$ device (MVRX, San Mateo US) (21) and the Mitral Loop Cerclage Catheter System ${ }^{\circledR}$ (Tau-PNU Medical, Seoul KOR) (22), but have not received commercial approval yet. The only direct annuloplasty device commercially available is the Cardioband ${ }^{\circledR}$ system (Edwards Lifesciences, Irvine US), with favorable early results in a study of 60 patients (23). At 12 months, seven patients (12\%) required a second intervention due to recurrent MR and $61 \%$ had moderate or less MR (24).

Transcatheter chordal repair is an off-pump surgical procedure through a transapical access aiming to restore physiological leaflet movement through the implantation of artificial ePTFE chords. The Harpoon ${ }^{\circledR}$ (Edwards Lifesciences, Irvine US) and the NeoChord ${ }^{\circledR}$ (NeoChord, St. Louis Park US) systems are based on this principle and are both commercially available. Harpoon has received CE mark after the recent presentation of the 1-year outcome data of the Mitral TRansApical neoChordal Echo-guided Repair (TRACER) Trial.
TABLE 2 | Advantages and disadvantages of transcatheter mitral valve repair and replacement.

\begin{tabular}{ll}
\hline Transcatheter mitral valve & $\begin{array}{l}\text { Transcatheter mitral valve } \\
\text { repair }\end{array}$
\end{tabular}

High procedural safety

MR reduction

anatomy-dependent and not

always predictable

Limited interaction with the

native anatomy

Low thrombogenicity

Risk of MR recurrence during long-term (?)

Some procedural risks

High efficacy in terms of MR reduction (one system fits all pathologies?)

Risk of LVOT obstruction and interaction with the subvalvular apparatus

Elevated risk of valve thrombosis Durable result (?)

Neochord has the largest experience with 1,200 patients treated so far. Safety and feasibility as well as durability could be demonstrated in the TACT trial and by registry data (25-27).

While transcatheter treatment options for mitral valve repair have evolved rapidly over the last years, the field of transcatheter mitral valve replacement (TMVR) is still in its infancy, mainly limited by the high rate of screening failure due to unsuitable anatomy. Advantages and disadvantages of TMVR compared to repair techniques are summarized in Table 2. Two approaches are currently being pursued: the off-label use of transcatheter heart valves that have been originally designed for the aortic position (mainly for valve-in-valve, valve-in-ring and valvein-MAC interventions) and the use of dedicated devices. The recently reported early results of the global feasibility trial with the Tendyne ${ }^{\circledR}$ prosthesis (Abbott Structural, Santa Clara US) represent the largest experience with TMVR in native mitral valves. The system has obtained CE mark approval in January 2020. Despite high technical success and procedural safety, allcause mortality and hospitalization for heart failure at 1-year follow-up were both substantial (26 and 31\%, respectively) (28, 29). Several other devices are currently evaluated in clinical trials, such as the Intrepid ${ }^{\circledR}$ TMVR system (Medtronic, Minneapolis US) for which favorable results have been reported in a 
pivotal study (30). Among the issues that still need to be addressed, obstruction of the left ventricular outflow tract, valve thrombogenicity and access route are probably the most salient.

\section{Current Indications and Limitations}

In the field of mitral valve disease, surgical treatment continues to play a predominant role. Nonetheless, transcatheter treatment is gaining increased significance for specific clinical scenarios and poses a viable treatment option for well-selected patients.

\section{Primary MR}

Surgery represents the standard of care for primary MR owing to excellent efficacy and long-term results of mitral valve repair and should be preferred over replacement when valve anatomy is suitable and perioperative risk acceptable $(15,31)$. In patients with prohibitive surgical risk (generally due to age), a transcatheter treatment should be evaluated by the interdisciplinary Heart Team. Depending on the individual anatomy of the valve and the subvalvular apparatus, an edge-toedge repair, chordal replacement or mitral valve replacement can be considered (32).

\section{Secondary MR}

Guideline-directed medical treatment together with cardiac resynchronization (if indicated) are the essential initial therapeutic steps. In patients with persisting symptomatic MR despite these measures, a corrective intervention should be considered. Evidence supporting surgical treatment in this setting is weak and survival benefit as well as result durability are uncertain $(33,34)$. However, patients who require coronary artery bypass grafting should undergo concomitant surgical valve treatment of severe MR (15). The eligibility for edge-to-edge repair, annuloplasty or valve replacement has to be assessed individually using multimodality imaging. The combination of different devices, e.g. different edge-to-edge systems or edge-to-edge and annuloplasty, may offer an even more individualized approach.

\section{Bridge to Circulatory Support or Heart Transplantation}

Patients with advanced heart failure should be first evaluated for circulatory support and heart transplantation. As an adjunctive option, edge-to-edge reconstruction of the mitral valve may stabilize the disease and hence, delay the need for a leftventricular assist device. In COAPT, progression of disease in terms of further decrease in left ventricular function and increase in LV dilation could be contained using the MitraClip (35) and the number of implanted assist-devices and heart transplants was significantly lower in the interventional group (4.4 vs. 9.5\%, $P=$ 0.01) (11).

\section{Acute Severe Mitral Regurgitation}

Acute mitral regurgitation usually requires prompt surgical treatment while time to surgery can be bridged by stabilization with an intra-aortic balloon pump (IABP) or Impella in addition to medical therapy (36). Several case reports and registry data have reported emergent edge-to-edge reconstruction to be a feasible alternative in selected patients (37-40).

\section{Rheumatic Mitral Stenosis}

Given favorable valve morphology, percutaneous balloon valvuloplasty remains the treatment of choice in symptomatic patients (15). In heavily calcified anatomies, concomitant mitral regurgitation or severe subvalvular disease, surgical intervention is generally the only option.

\section{Valve-in-Valve, Valve-in Ring and Valve-in-MAC}

Valve-in-valve treatment of degenerated bioprostheses in the mitral position is an option, especially in older patients with prohibitive risk for a redo surgical procedure. A recently published multicenter registry has shown excellent results for ViV procedures, whereas Valve-in-ring and TMVR in heavy calcified mitral valves (MAC) were associated with rather high rates of procedural complications and mortality (41). The use of a dedicated prosthesis in patients with MAC may lead to better clinical outcomes as demonstrated by the recent experience with the Tendyne valve (42). For mitral valve replacement strategies, an important limitation is the potential obstruction of the left ventricular outflow tract (LVOT) that needs to be evaluated carefully by pre-procedural imaging like $4 \mathrm{D}$ computed tomography and 3D-reconstruction, as well as 3D-printing for implantation simulation (43-45). Intentional laceration of the anterior mitral valve leaflet (LAMPOON) or preemptive alcohol septal ablation have been introduced as techniques to prevent outflow obstruction $(46,47)$.

\section{What the Future Holds}

Further research is needed to broaden the evidence of transcatheter devices, observe long-term clinical outcomes and durability, and evaluate procedural success in larger patient cohorts. Several ongoing studies aim to show the benefit of transcatheter treatment compared to medical therapy, surgical treatment, or in head-to-head comparison of different devices. The CLASP IID/F study, for example, evaluates the safety and efficacy of the PASCAL system compared to the MitraClip system in a non-inferiority design. Other transcatheter devices are currently awaiting commercial approval by the FDA and/or CE mark, like the Millipede IRIS ${ }^{\circledR}$ (Millipede, Boston Scientific, Marlborough US) for direct annuloplasty (48). New iterations of the MitraClip system will provide wider clip arms, direct measurement of left atrial pressure, as well as optional independent leaflet grasping. The RESHAPE-HF2 trial (RandomizEd Study of tHe MitrACliP DEvice in Heart Failure Patients With Clinically Significant Functional Mitral Regurgitation) aims to provide further evidence for the use of the MitraClip System in chronic heart failure patients (49), whereas the MATTERHORN trial (Mitral vAlve reconsTrucTion for advancEd Insufficiency of Functional or iscHemic ORigiN) is comparing MitraClip to reconstructive mitral valve surgery (50). Research seeking better understanding of the pathophysiology and natural history of disease progression will enable better patient selection and targeted, individualized device therapy.

Incipiently, many devices have been developed for the transapical access, but especially in patients with secondary MR and preexisting LV dysfunction, this approach has been associated with high mortality. Currently, existing systems 
are modified and miniaturized to be introduced via the transfemoral/-septal access, thereby reducing the invasiveness of the procedure and decreasing peri-procedural complications. Compared to mitral valve repair, valve replacement has the advantage that, especially in patients with a complex anatomy, a nearly complete resolution of $\mathrm{MR}$ can be achieved. In addition, the subvalvular apparatus remains intact. The future of transcatheter mitral valve interventions might therefore be a transseptal valve replacement in the vast majority of patients, but several technical challenges have to be overcome and open questions, like the optimal patient selection and appropriate antithrombotic management, need to be addressed upfront.

\section{TRICUSPID VALVE INTERVENTIONS}

\section{State of the Art}

Severe tricuspid regurgitation (TR) has been neglected in the past, as it is mainly associated with left-sided heart problems, but also often underestimated due to challenging imaging and grading. Meanwhile, several studies have shown TR to be an independent prognostic predictor of worse clinical outcome and poor survival $(2,51,52)$. However, due to age, co-morbidities and generally advanced stage of the disease, surgical treatment is often no longer a reasonable option at the time of clinical presentation. Nevertheless, the case volume of tricuspid valve repair and replacement both have increased over the last years, but in-hospital mortality after tricuspid valve surgery remains stable $(8.8 \%)(53,54)$. In addition, surgery is associated with a longer hospital stay and substantial costs.

Subsequently, new transcatheter treatment options have emerged. Since most procedures were adapted from left atrioventricular valve interventions, they follow similar underlying principles: edge-to-edge repair enhancing leaflet coaptation, annuloplasty aiming for annular size reduction and valve replacement.

The most widely used transcatheter technique so far is the MitraClip system with encouraging results (55-58): reverse remodeling of the right ventricle (59) and improved cardiac output (60). In patients with previously elevated liver enzymes due to congestion a significant reduction could be demonstrated (61).

The Cardioband direct annuloplasty system (Edwards Lifesciences, Irvine US) has recently obtained CE approval for the treatment of functional TR, based on the results of a prospective observational study, which showed high technical success (100\%) and significant improvement of functional status (88\% of patients in NYHA class I-II after 6 months) (62).

Other transcatheter approaches, such as direct annuloplasty using a caval anchoring stent, the TriCinch system, 4TECH, Galway IRL (63) or the implantation of bicaval stenting devices [e.g., TRICENTO, NVT, Hechingen DE (64)], are currently under clinical investigation.

Transcatheter tricuspid valve replacement (65) is a promising alternative. However, complete resolution of TR may be critical in patients with advanced RV dysfunction due to potential RV failure especially in patients with previously described pulmonary hypertension (66).

The hitherto evidence is largely derived from registry data and case reports. The TriValve Registry is the first large scale international database collecting data on transcatheter tricuspid valve interventions. The mid-term results reported a procedural success rate of $72.8 \%$ with no difference among the different devices (66\% MitraClip, 9\% CAVI, 8\% FORMA, 6\% Trialign, $4 \%$ Cardioband, $4 \%$ TriCinch, $3 \%$ others). Procedural failure (residual TR $\geq$ grade $2+$ was identified as a predictor of adverse outcomes. Peri-procedural mortality was $0 \%$ and MACCE occurred in $10.3 \%$ at 30 -days follow-up (67).

A recently published propensity matched case-control study comparing transcatheter valve therapy to medical treatment alone further support the current development. In the 268 patients from the TriValve registry that were matched to solely medically managed patients, TTVI was associated with a survival benefit (mortality $23 \pm 3 \%$ vs. $36 \pm 3 \%, p=0.001$ ), as well as a reduction of rehospitalization for heart failure ( $26 \pm 3 \%$ vs. $47 \pm$ $3 \% p<0.0001$ ) at 1 -year follow-up (68).

\section{Current Indications And Limitations}

Transcatheter tricuspid valve interventions (TTVI) pose a number of anatomical and technical challenges. Thinner leaflets and larger coaptation gaps render leaflet approximation more difficult than on the left side. Routine use of the PASCAL and the new iteration of the MitraClip XTR system, both featuring extended arms, may facilitate grasping (69).

The choice of the right treatment option for patients with severe TR remains the main challenge. Figure 2 attempts to propose a possible decision algorithm based on clinical experience and the data available so far. Importantly, patients with TR induced by a cardiac implantable electronic device lead may also benefit from transcatheter treatment and the same decision criteria apply. To determine eligibility for annuloplasty, caval stent/valve implantation and valve replacement, advanced imaging including multidetector computed tomography and 3D TEE are necessary. In case of advanced disease, combined procedures may be evaluated (e.g., sequential annuloplasty and edge-to-edge repair).

Recent data (70) also suggest the importance of a global approach to combined mitral and tricuspid valve disease as illustrated in Figure 3.

\section{What the Future Holds}

Patients with severe TR represent a complex and heterogeneous population, and identifying the optimal method and timing of treatment are crucial. Strategies adapted to the individual stage of the disease are necessary. Further research is needed to better understand the incidence, pathophysiology and underlying mechanisms governing disease progression. Development of new and validation of established imaging techniques are required for more accurate and reproducible grading of TR severity, as well as anatomical screening.

Dedicated prospective randomized trials are necessary to determine the true clinical benefit of TR correction. 


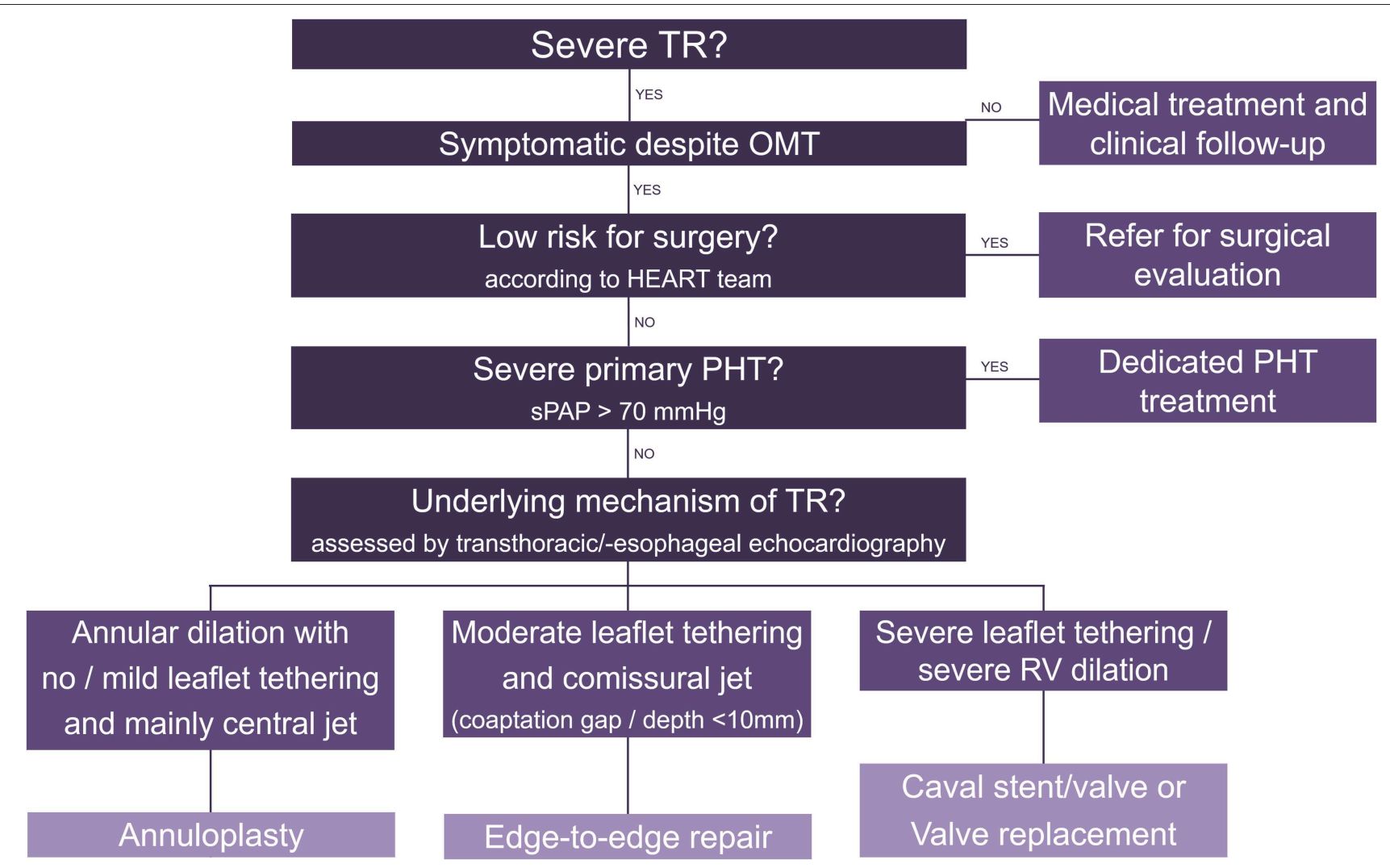

FIGURE 2 | Decision algorithm for transcatheter tricuspid valve interventions. TR, tricuspid regurgitation; OMT, optimal medical therapy; PHT, pulmonary hypertension; RV, right ventricle.
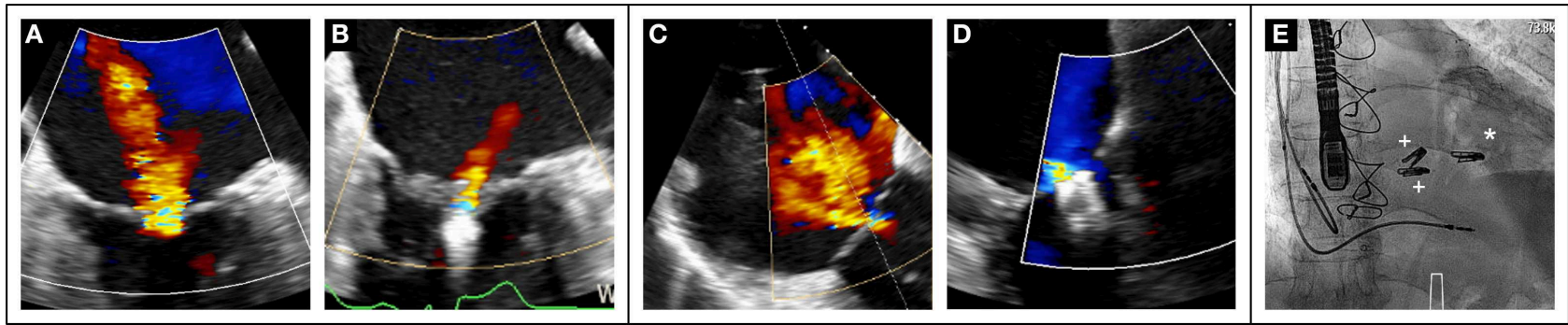

FIGURE 3 | Case of combined mitral and tricuspid edge-to-edge repair in a 79-year old sympatomatic (NYHA III) male patient with prohibitive surgical risk (Euroscore II 21\%). Baseline transesophageal assessment showed severe MR (A). After transseptal puncture, the mitral valve was treated first with the placement of one MitraClip XTR. with MR reduction to grade 1+ (B). Severe TR at baseline (C) Two MitraClip XTR were placed in the anteroseptal commissure with reduction of TR to mild (D). Final fluoroscopic result ((E), "MitraClip mitral, + MitraClips tricuspid).

\section{SUMMARY}

Over the last years, numerous transcatheter techniques for the treatment of mitral and tricuspid valve disease have been introduced. Patient volume will substantially increase over the next years and clinical indications further expand. In contrast to transcatheter aortic valve implantation, percutaneous treatment of the mitral and tricuspid valves will to a lesser extent represent an alternative to surgery, but rather address the needs of a large population of patients that has been undertreated so far.

\section{AUTHOR CONTRIBUTIONS}

All authors have made substantial contributions to the conception of the work. It has been drafted by MW and FP and has been critically revised by all authors for important intellectual content. All authors have given their approval for publication of the content and have agreed to be accountable for all aspects of the work in ensuring that questions related to the accuracy or integrity of any part of the work are appropriately investigated and resolved. 


\section{REFERENCES}

1. Nkomo VT, Gardin JM, Skelton TN, Gottdiener JS, Scott CG, EnriquezSarano M. Burden of valvular heart diseases: a population-based study. Lancet. (2006) 368:1005-11. doi: 10.1016/S0140-6736(06)69208-8

2. Topilsky Y, Maltais S, Medina Inojosa J, Oguz D, Michelena H, Maalouf J, et al. Burden of tricuspid regurgitation in patients diagnosed in the community setting. JACC Cardiovasc Imaging. (2018) 12:433-42. doi: 10.1016/j.jcmg.2018.06.014

3. Moore M, Chen J, Mallow PJ, Rizzo JA. The direct health-care burden of valvular heart disease: evidence from US national survey data. ClinicoEcon Outcomes Res. (2016) 8:613-27. doi: 10.2147/CEOR.S112691

4. Andalib A, Mamane S, Schiller I, Zakem A, Mylotte D, Martucci G, et al. A systematic review and meta-analysis of surgical outcomes following mitral valve surgery in octogenarians: implications for transcatheter mitral valve interventions. EuroIntervention. (2014) 9:1225-34. doi: 10.4244/EIJV9I10A205

5. Mirabel M, Iung B, Baron G, Messika-Zeitoun D, Detaint D, Vanoverschelde $\mathrm{JL}$, et al. What are the characteristics of patients with severe, symptomatic, mitral regurgitation who are denied surgery? Eur Heart J. (2007) 28:135865. doi: 10.1093/eurheartj/ehm001

6. Nishimura RA, Vahanian A, Eleid MF, Mack MJ. Mitral valve diseasecurrent management and future challenges. Lancet. (2016) 387:132434. doi: 10.1016/S0140-6736(16)00558-4

7. Ailawadi G, Lim DS, Mack MJ, Trento A, Kar S, Grayburn PA, et al. One-year outcomes after mitraclip for functional mitral regurgitation. Circulation. (2019) 139:37-47. doi: 10.1161/CIRCULATIONAHA.117. 031733

8. Maisano F, Franzen O, Baldus S, Schafer U, Hausleiter J, Butter C, et al. Percutaneous mitral valve interventions in the real world: early and 1-year results from the ACCESS-EU, a prospective, multicenter, nonrandomized post-approval study of the mitraclip therapy in Europe. J Am Coll Cardiol. (2013) 62:1052-61. doi: 10.1016/j.jacc.2013.02.094

9. Feldman T, Kar S, Elmariah S, Smart SC, Trento A, Siegel RJ, et al. Randomized comparison of percutaneous repair and surgery for mitral regurgitation: 5-year results of EVEREST II. J Am Coll Cardiol. (2015) 66:2844-54. doi: 10.1016/j.jacc.2015.10.018

10. Obadia JF, Messika-Zeitoun D, Leurent G, Iung B, Bonnet G, Piriou $\mathrm{N}$, et al. Percutaneous repair or medical treatment for secondary mitral regurgitation. N Engl J Med. (2018) 379:2297-306. doi: 10.1056/NEJMoa 1805374

11. Stone GW, Lindenfeld J, Abraham WT, Kar S, Lim DS, Mishell JM, et al. Transcatheter mitral-valve repair in patients with heart failure. $\mathrm{N} \mathrm{Engl} \mathrm{J} \mathrm{Med.}$ (2018) 379:2307-18. doi: 10.1056/NEJMoa1806640

12. Mack MJ. COAPT: 3-year outcomes from a randomized trial of the MitraClip in patients with heart failure and severe secondary mitral regurgitation. In: TCT Congress 09/2019. San Francisco, CA (2019).

13. Praz F, Grasso C, Taramasso M, Baumbach A, Piazza N, Tamburino C, et al. Mitral regurgitation in heart failure: time for a rethink. Eur Heart J. (2019) 40:2189-93. doi: 10.1093/eurheartj/ehz222

14. Baumgartner H, Falk V, Bax JJ, De Bonis M, Hamm C, Holm PJ, et al. 2017 ESC/EACTS guidelines for the management of valvular heart disease. Eur Heart J. (2017) 38:2739-91. doi: 10.5603/KP.2018.0013

15. Nishimura RA, Otto CM, Bonow RO, Carabello BA, Erwin JP III, Guyton RA, et al. 2014 AHA/ACC guideline for the management of patients with valvular heart disease: a report of the American college of cardiology/american heart association task force on practice guidelines. J Am Coll Cardiol. (2014) 63:e57-185. doi: 10.1161/CIR.00000000000 00029

16. Praz F, Braun D, Unterhuber M, Spirito A, Orban M, Brugger N, et al. Edge-to-edge mitral valve repair with extended clip arms: early experience from a multicenter observational study. JACC Cardiovasc Interv. (2019) 12:1356. doi: 10.1016/j.jcin.2019.03.023

17. Praz F, Spargias K, Chrissoheris M, Bullesfeld L, Nickenig G, Deuschl $\mathrm{F}$, et al. Compassionate use of the PASCAL transcatheter mitral valve repair system for patients with severe mitral regurgitation: a multicentre, prospective, observational, first-in-man study. Lancet. (2017) 390:77380. doi: $10.1016 /$ S0140-6736(17)31600-8
18. Lim DS, Kar S, Spargias K, Kipperman RM, O’Neill WW, Ng MKC, et al. Transcatheter valve repair for patients with mitral regurgitation: 30day results of the CLASP study. JACC Cardiovasc Interv. (2019). 12:136978. doi: 10.1016/j.jcin.2019.04.034

19. Siminiak T, Wu JC, Haude M, Hoppe UC, Sadowski J, Lipiecki J, et al. Treatment of functional mitral regurgitation by percutaneous annuloplasty: results of the TITAN Trial. Eur J Heart Fail. (2012) 14:9318. doi: 10.1093/eurjhf/hfs076

20. Witte KK, Lipiecki J, Siminiak T, Meredith IT, Malkin CJ, Goldberg SL, et al. The REDUCE FMR trial: a randomized sham-controlled study of percutaneous mitral annuloplasty in functional mitral regurgitation. JACC Heart Fail. (2019). 7:945-55. doi: 10.1016/j.jchf.2019.06.011

21. Erglis A, Narbute I, Poupineau M, Hovasse T, Kamzola G, Zvaigzne L, et al. Treatment of secondary mitral regurgitation in chronic heart failure. J Am Coll Cardiol. (2017) 70:2834-5. doi: 10.1016/j.jacc.2017.09.1110

22. Park YH, Chon MK, Lederman RJ, Sung SC, Je HG, Choo KS, et al. Mitral loop cerclage annuloplasty for secondary mitral regurgitation: first human results. JACC Cardiovasc Interv. (2017) 10:597-610. doi: 10.1016/j.jcin.2016. 12.282

23. Schueler R, Malasa M, Hammerstingl C, Nickenig G. Transcatheter interventions for tricuspid regurgitation: MitraClip. EuroIntervention. (2016) 12:Y108-9. doi: 10.4244/EIJV12SYA29

24. Messika-Zeitoun D, Nickenig G, Latib A, Kuck KH, Baldus S, Schueler R, et al. Transcatheter mitral valve repair for functional mitral regurgitation using the cardioband system: 1 year outcomes. Eur Heart J. (2019) 40:46672. doi: 10.1093/eurheartj/ehy424

25. Kiefer P, Meier S, Noack T, Borger MA, Ender J, Hoyer A, et al. Good 5-year durability of transapical beating heart off-pump mitral valve repair with neochordae. Ann Thorac Surg. (2018) 106:440-5. doi: 10.1016/j.athoracsur.2018.01.092

26. Seeburger J, Rinaldi M, Nielsen SL, Salizzoni S, Lange R, Schoenburg M, et al. Off-pump transapical implantation of artificial neo-chordae to correct mitral regurgitation: the TACT trial (transapical artificial chordae tendinae) proof of concept. J Am Coll Cardiol. (2014) 63:914-9. doi: 10.1016/j.jacc.2013. 07.090

27. Colli A, Manzan E, Aidietis A, Rucinskas K, Bizzotto E, Besola L, et al. An early European experience with transapical off-pump mitral valve repair with NeoChord implantation. Eur J Cardio Thorac Surg. (2018) 54:4606. doi: 10.1093/ejcts/ezy064

28. Muller DWM, Farivar RS, Jansz P, Bae R, Walters D, Clarke A, et al. Transcatheter mitral valve replacement for patients with symptomatic mitral regurgitation: a global feasibility trial. J Am Coll Cardiol. (2017) 69:38191. doi: 10.1016/j.jacc.2016.10.068

29. Sorajja P, Moat N, Badhwar V, Walters D, Paone G, Bethea B, et al. Initial feasibility study of a new transcatheter mitral prosthesis: the first 100 patients. J Am Coll Cardiol. (2019) 73:1250-60. doi: 10.1016/j.jacc.2018. 12.066

30. Bapat V, Rajagopal V, Meduri C, Farivar RS, Walton A, Duffy SJ, et al. Early experience with new transcatheter mitral valve replacement. J Am Coll Cardiol. (2018) 71:12-21. doi: 10.1016/j.jacc.2017.10.061

31. Bolling SF, Li S, O’Brien SM, Brennan JM, Prager RL, Gammie JS. Predictors of mitral valve repair: clinical and surgeon factors. Ann Thorac Surg. (2010) 90:1904-11. doi: 10.1016/j.athoracsur.2010.07.062

32. Tabata N, Sugiura A, Tsujita K, Nickenig G, Sinning JM. Percutaneous interventions for mitral and tricuspid heart valve diseases. Cardiovasc Interven Ther. (2019). 35:62-71. doi: 10.1007/s12928-019-00610-z

33. Wu AH, Aaronson KD, Bolling SF, Pagani FD, Welch K, Koelling TM. Impact of mitral valve annuloplasty on mortality risk in patients with mitral regurgitation and left ventricular systolic dysfunction. J Am Coll Cardiol. (2005) 45:381-7. doi: 10.1016/j.jacc.2004.09.073

34. Wong DR, Agnihotri AK, Hung JW, Vlahakes GJ, Akins CW, Hilgenberg $\mathrm{AD}$, et al. Long-term survival after surgical revascularization for moderate ischemic mitral regurgitation. Ann Thorac Surg. (2005) 80:570-7. doi: 10.1016/j.athoracsur.2005.03.034

35. Arnold SV, Stone GW, Mack MJ, Chhatriwalla AK, Austin BA, Zhang Z, et al. COAPT investigators. Health status changes and outcomes in patients with heart failure and mitral regurgitation: From COAPT. J Am Coll Cardiol. (2020) doi: 10.1016/j.jacc.2020.03.002. [Epub ahead of print] 
36. Nishimura RA, Otto CM, Bonow RO, Carabello BA, Erwin JP III, Fleisher LA, et al. 2017 AHA/ACC focused update of the 2014 AHA/ACC guideline for the management of patients with valvular heart disease: a report of the american college of cardiology/american heart association task force on clinical practice guidelines. J Am Coll Cardiol. (2017) 70:25289. doi: 10.1016/j.jacc.2017.03.011

37. Adamo M, Curello S, Chiari E, Fiorina C, Chizzola G, Magatelli M, et al. Percutaneous edge-to-edge mitral valve repair for the treatment of acute mitral regurgitation complicating myocardial infarction: a single centre experience. Int J Cardiol. (2017) 234:53-7. doi: 10.1016/j.ijcard.2017. 02.072

38. Hernandez-Enriquez M, Freixa X, Sanchis L, Regueiro A, Burgos F, Navarro R, et al. MitraClip $\AA$ repair in cardiogenic shock due to acute mitral regurgitation: from near-death to walking. J Heart Valve Dis. (2018) 27:114-6.

39. Papadopoulos K, Chrissoheris M, Nikolaou I, Spargias K. Edge-toedge mitral valve repair for acute mitral valve regurgitation due to papillary muscle rupture: a case report. Eur Heart J Case Rep. (2019) 3:ytz001. doi: 10.1093/ehjcr/ytz001

40. Estevez-Loureiro R, Adamo M, Arzamendi D, Denti P, Freixa X, NombelaFranco L, et al. The european registry of mitraclip in acute mitral regurgitation following an acute myocardial infarction (EREMMI). EuroInterven. (2020) 15:1248-1250. doi: 10.4244/EIJ-D-19-00653

41. Yoon SH, Whisenant BK, Bleiziffer S, Delgado V, Dhoble A, Schofer N, et al. Outcomes of transcatheter mitral valve replacement for degenerated bioprostheses, failed annuloplasty rings, and mitral annular calcification. Eur Heart J. (2019) 40:441-51. doi: 10.1093/eurheartj/ehy590

42. Sorajja P, Gossl M, Babaliaros V, Rizik D, Conradi L, Bae R, Burke $\mathrm{RF}$, et al. Novel transcatheter mitral valve prosthesis for patients with severe mitral annular calcification. J Am Coll Cardiol. (2019) 74:143140. doi: 10.1016/j.jacc.2019.07.069

43. Wang DD, Eng M, Greenbaum A, Myers E, Forbes M, Pantelic M, et al. Predicting LVOT obstruction after TMVR. JACC Cardiovasc Imaging. (2016) 9:1349-52. doi: 10.1016/j.jcmg.2016.01.017

44. Praz F, Khalique OK, Lee R, Wu IY, Russell H, Guerrero M, et al. Imaging in patients with severe mitral annular calcification: insights from a multicentre experience using transatrial balloon-expandable valve replacement. Eur Heart J Cardiovasc Imaging. (2019) 20:1395-406. doi: 10.1093/ehjci/jez050

45. Meduri CU, Reardon MJ, Lim DS, Howard E, Dunnington G, Lee DP, et al. Novel multiphase assessment for predicting left ventricular outflow tract obstruction before transcatheter mitral valve replacement. JACC Cardiovasc Interv. (2019) 12:2402-12. doi: 10.1016/j.jcin.2019.06.015

46. Khan JM, Babaliaros VC, Greenbaum AB, Foerst JR, Yazdani S, McCabe $\mathrm{JM}$, et al. Anterior leaflet laceration to prevent ventricular outflow tract obstruction during transcatheter mitral valve replacement. J Am Coll Cardiol. (2019) 73:2521-34. doi: 10.1016/j.jacc.2019.02.076

47. Wang DD, Guerrero M, Eng MH, Eleid MF, Meduri CU, Rajagopal V, et al. Alcohol septal ablation to prevent left ventricular outflow tract obstruction during transcatheter mitral valve replacement: first-in-man study. JACC Cardiovasc Interv. (2019) 12:1268-79. doi: 10.1016/j.jcin.2019. 02.034

48. Rogers JH, Boyd WD, Smith TW, Bolling SF. Early experience with millipede IRIS transcatheter mitral annuloplasty. Ann Cardiothorac Surg. (2018) 7:7806. doi: $10.21037 /$ acs.2018.10.05

49. A Clinical evaluation of the safety and effectiveness of the mitraclip system in the treatment of clinically significant functional mitral regurgitation (reshape-HF2) (ClinicalTrials.gov Identifier: NCT02444338). Available online at: https://clinicaltrials.gov/ct2/show/NCT02444338

50. A multicenter, randomized, controlled study to assess mitral valve reconstruction for advanced insufficiency of functional or iscHemic ORigiN (MATTERHORN) (ClinicalTrials.gov Identifier: NCT02371512). Available online at: https://clinicaltrials.gov/ct2/show/NCT02371512

51. Sagie A, Schwammenthal E, Newell JB, Harrell L, Joziatis TB, Weyman $\mathrm{AE}$, et al. Significant tricuspid regurgitation is a marker for adverse outcome in patients undergoing percutaneous balloon mitral valvuloplasty. J Am Coll Cardiol. (1994) 24:696-702. doi: 10.1016/0735-1097(94) 90017-5
52. Nath J, Foster E, Heidenreich PA. Impact of tricuspid regurgitation on long-term survival. J Am Coll Cardiol. (2004) 43:4059. doi: 10.1016/j.jacc.2003.09.036

53. Zack CJ, Fender EA, Chandrashekar P, Reddy YNV, Bennett CE, Stulak $\mathrm{JM}$, et al. National trends and outcomes in isolated tricuspid valve surgery. J Am Coll Cardiol. (2017) 70:2953-60. doi: 10.1016/j.jacc.2017. 10.039

54. Alqahtani F, Berzingi CO, Aljohani S, Hijazi M, Al-Hallak A, Alkhouli M. Contemporary trends in the use and outcomes of surgical treatment of tricuspid regurgitation. J Am Heart Assoc. (2017) 6:e007597. doi: 10.1161/JAHA.117.007597

55. Braun D, Nabauer M, Orban M, Englmaier A, Rosler D, Hagl C, et al. One-year results of transcatheter treatment of severe tricuspid regurgitation using the edge-to-edge repair technique. EuroIntervention. (2018) 14:e4135. doi: 10.4244/EIJ-D-18-00186

56. Nickenig G, Kowalski M, Hausleiter J, Braun D, Schofer J, Yzeiraj $\mathrm{E}$, et al. Transcatheter treatment of severe tricuspid regurgitation with the edge-to-edge mitraclip technique. Circulation. (2017) 135:1802-14. doi: 10.1161/CIRCULATIONAHA.116.024848

57. Mehr M, Taramasso M, Besler C, Ruf T, Connelly KA, Weber M, et al. 1 -year outcomes after edge-to-edge valve repair for symptomatic tricuspid regurgitation: results from the trivalve registry. JACC Cardiovasc Interven. (2019) 12:1451-61. doi: 10.1016/j.jcin.2019.04.019

58. Nickenig G, Weber M, Lurz P, von Bardeleben RS, Sitges M, Sorajja $\mathrm{P}$, et al. Transcatheter edge-to-edge repair for reduction of tricuspid regurgitation: 6-month outcomes of the TRILUMINATE singlearm study. Lancet. (2019) 394:2002-11. doi: 10.1016/S0140-6736(19) 32600-5

59. Orban M, Braun D, Deseive S, Stolz L, Stocker TJ, Stark K, et al. Transcatheter edge-to-edge repair for tricuspid regurgitation is associated with right ventricular reverse remodeling in patients with right-sided heart failure. JACC Cardiovasc Imaging. (2019) 12:559-60. doi: 10.1016/j.jcmg.2018. 10.029

60. Rommel KP, Besler C, Noack T, Blazek S, von Roeder M, Fengler K, et al. Physiological and clinical consequences of right ventricular volume overload reduction after transcatheter treatment for tricuspid regurgitation. JACC Cardiovasc Interv. (2019) 12:1423-34. doi: 10.1016/j.jcin.2019. 02.042

61. Karam N, Braun D, Mehr M, Orban M, Stocker TJ, Deseive S, et al. Impact of transcatheter tricuspid valve repair for severe tricuspid regurgitation on kidney and liver function. JACC Cardiovasc Interv. (2019) 12:141320. doi: 10.1016/j.jcin.2019.04.018

62. Nickenig G, Weber M, Schueler R, Hausleiter J, Nabauer M, von Bardeleben RS, et al. 6-Month outcomes of tricuspid valve reconstruction for patients with severe tricuspid regurgitation. J Am Coll Cardiol. (2019) 73:190515. doi: 10.1016/j.jacc.2019.01.062

63. Taramasso M, Nietlispach F, Zuber M, Maisano F. Transcatheter repair of persistent tricuspid regurgitation after mitraclip with the tricinch system: interventional valve treatment toward the surgical standard. Eur Heart J. (2017) 38:1259. doi: 10.1093/eurheartj/ehw541

64. Montorfano M, Beneduce A, Ancona MB, Ancona F, Sgura F, Romano V, et al. Tricento transcatheter heart valve for severe tricuspid regurgitation: procedural planning and technical aspects. JACC Cardiovasc Interv. (2019) 12:e189-91. doi: 10.1016/j.jcin.2019. 07.010

65. Hahn RT, George I, Kodali SK, Nazif T, Khalique OK, Akkoc D, et al. Early single-site experience with transcatheter tricuspid valve replacement. JACC Cardiovasc Imaging. (2019) 12:416-429. doi: 10.1016/j.jcmg.2018. 08.034

66. Krishnaswamy A, Navia J, Kapadia SR. Transcatheter tricuspid valve replacement. Interv Cardiol Clin. (2018) 7:6570. doi: 10.1016/j.iccl.2017.08.009

67. Taramasso M, Alessandrini H, Latib A, Asami M, Attinger-Toller A, Biasco L, et al. Outcomes after current transcatheter tricuspid valve intervention: mid-term results from the international trivalve registry. JACC Cardiovasc Interv. (2019) 12:155-65. doi: 10.1016/j.jcin.2018. 10.022 
68. Taramasso M, Benfari G, van der Bijl P, Alessandrini H, AttingerToller A, Biasco L, et al. Transcatheter versus medical treatment of symptomatic severe tricuspid regurgitation. J Am Coll Cardiol. (2019) 74:2998-3008. doi: 10.1016/j.jacc.2019.09.028

69. Fam NP, Ho EC, Zahrani M, Samargandy S, Connelly KA. Transcatheter tricuspid valve repair with the PASCAL system. JACC Cardiovasc Interv. (2018) 11:407-8. doi: 10.1016/j.jcin.2017. 12.004

70. Besler C, Blazek S, Rommel KP, Noack T, von Roeder M, Luecke C, et al. Combined mitral and tricuspid versus isolated mitral valve transcatheter edge-to-edge repair in patients with symptomatic valve regurgitation at high surgical risk. JACC Cardiovas Interv. (2018) 11:1142-51. doi: 10.1016/j.jcin.2018. 04.010
Conflict of Interest: PW received lecture and proctoring fees from Edwards Lifesciences and Medtronic.

The remaining authors declare that the research was conducted in the absence of any commercial or financial relationships that could be construed as a potential conflict of interest.

Copyright (c) 2020 Winkel, Praz and Wenaweser. This is an open-access article distributed under the terms of the Creative Commons Attribution License (CC BY). The use, distribution or reproduction in other forums is permitted, provided the original author(s) and the copyright owner(s) are credited and that the original publication in this journal is cited, in accordance with accepted academic practice. No use, distribution or reproduction is permitted which does not comply with these terms. 